\title{
Platelet Count as a Prognostic Indicator in Burn Septicemia
}

\author{
Ashok Surybhanji Gajbhiye • M. M. Meshram • \\ Amrish P. Kathod
}

Received: 6 February 2012 / Accepted: 28 May 2012 / Published online: 12 July 2012

(C) Association of Surgeons of India 2012

\begin{abstract}
Evaluation of platelet count and its significance in early detection of post burn septicemia for commencement of timely vigorous treatment against it. Studies investigating the role of platelets and platelet count in burn patients are rare, rather old and mostly presenting case reports. Septicemia is the most important cause of mortality in burns. Burn patients can only be saved if septicemia is detected early which requires very sensitive prognostic indicator. Total 594 adult burn patients were studied, by observing them for septicemia and studying their subsequent platelet counts using visual method. In non-survivors (256) gradual decline in platelet count was observed and minimal platelet count was observed before death of the patient, while in survivors (338) gradual rise in platelet count was observed. No significant variation observed in other laboratory parameters such as total neutrophil count and serum creatinine. In significant number of non survivor (62.11\%) platelet count was low before their death and in significant number of survivor $(86.09 \%)$ platelet count was normal before their discharge. Thus it is conclude that serial declining platelet count is a very sensitive prognostic factor in early detection of post burn septicemia.
\end{abstract}

This original article is not presented or sent in any other journal for publication other than Indian journal of surgery.

A. S. Gajbhiye $(\bowtie) \cdot$ M. M. Meshram · A. P. Kathod

Department of General Surgery,

Indira Gandhi Government Medical College,

Central Avenue road,

Nagpur -18 Maharashtra, India

e-mail: gsashok72@yahoo.in

A. S. Gajbhiye

e-mail: gsashok1972@gmail.com

A. S. Gajbhiye

Plot no- 54, kalpataru nagar, Besa Road,

Nagpur -34 Manewada, India
Keywords Platelet $\cdot$ Burn $\cdot$ Septicemia

\section{Introduction}

Platelets play an important role in severe hemostasis disorders and immune response impairments in burn patients. Platelets are small fragments of megakaryocyte cytoplasm, which play a fundamental role in primary and secondary hemostasis, as crucial reactions of the coagulation cascade occur on their phospholipid surface. Although their primary function is hemostatic regulation, they also act as inflammatory cells. They release inflammatory mediators, express proinflammatory surface molecules, interact with leukocytes and endothelial cells, thus taking part in the induction of acute and chronic immune responses [1].

Burn injury is very common and the incidence of burn is 1.1 per 1,00,000 populations according to Michael Peck in epidemiology of burn injuries globally. The majority of burn injuries are minor although painful. In contrast, a small number of individuals receive massive, deep burns that are accompanied by permanent disfigurement or death. Traditionally, burn area and patient's age have been employed as the primary predictors of mortality after thermal injury. Other factors identified during the course of hospitalization also may help to predict accurately those patients who are likely to die [2].

Long before in 1977, Raymond C. Vilain raised a question: Is the burn center a septic ghetto? This is very true even today, because every new arriving burned patient directly goes to the burn ward where already existing infected patients, contaminated floors, and beds are ready to welcome this burned patient [3].

Thrombocytopenia is almost universal in bacterial infections associated with bacteremia and is usually the result of increased platelet consumption. The reduced platelet count may be an isolated finding or may be associated with 
Table 1 Mean platelet count in survivors

\begin{tabular}{|c|c|c|c|c|c|c|c|}
\hline \multirow[t]{2}{*}{ S. No. } & \multirow[t]{2}{*}{ Burn groups } & \multirow[t]{2}{*}{ Number of patients } & \multicolumn{5}{|c|}{ Mean platelet count (in lakh/mm $/ \mathrm{mm}^{3}$ ) } \\
\hline & & & 1st day & 3rd day & 7th day & 14th day & 21 st day \\
\hline 1 & $20-30 \%$ & 173 & $2.02 \pm 0.4$ & $2.07 \pm 0.48$ & $2.0 \pm 0.64$ & $2.15 \pm 0.53$ & $2.28 \pm 0.6$ \\
\hline 2 & $31-40 \%$ & 146 & $2.03 \pm 0.34$ & $2.07 \pm 0.63$ & $2.1 \pm 0.49$ & $2.12 \pm 0.24$ & $2.35 \pm 0.47$ \\
\hline \multirow[t]{2}{*}{3} & $41-50 \%$ & 19 & $1.99 \pm 0.31$ & $2.03 \pm 0.46$ & $2.08 \pm 0.28$ & $2.1 \pm 0.28$ & $2.14 \pm 0.73$ \\
\hline & Total & 338 & & & & & \\
\hline
\end{tabular}

disseminated intravascular coagulopathy. Thrombocytopenia usually occurs early and can be an early indication of bacteremia in burn patients [4-7].

Sepsis remains the major cause of death in burn patients. The moment there is invasion of microorganisms into the systemic circulation, the patient develops septicemia. Once the patient develops septicemia, it affects almost all the organ systems of the body, leading to systemic inflammatory response syndrome, followed by multiple organ dysfunction syndrome with death as an ultimate effect.

Hence, burn patients can only be saved in early phase of septicemia before the occurrence of irreversible damage to various organs. Declining platelet count occurs very early in septicemia even before clinical signs and symptoms develop. This requires the presence of sensitive parameters which can detect septicemia in its early phase, so that early detection and institution of treatment can save the life of burn patients.

\section{Patients and Methods}

The following study was carried out in the burn unit at Indira Gandhi Government Medical College, Nagpur, from July 2002 to February 2012. During the study period, a total of 598 patients within the age group of 15 years and above who were admitted to the burn ward in emergency and routine, irrespective of sex of the patient, were included in this study. In less than $20 \%$ total body surface area burn cases, septicemia was seen in a less number of patients. More than $70 \%$ total body surface area burn cases who had very high and early mortality and who died because of hypovolemic shock were excluded from this study.

For estimation of platelet count, $2 \mathrm{ml}$ of venous blood was collected in EDTA bulb (as anticoagulant) and gently mixed without delay. To this $0.1 \mathrm{ml}$ of blood in $1.9 \mathrm{ml}$ of diluent ( 1 in 20 dilution) was added. The diluent agent used was $10 \mathrm{~g} / \mathrm{l}$ ammonium oxalate. The Neubauer counting chamber was filled with suspension and placed in moist petri dish and left for 20 minutes to settle the platelets. Platelets appeared under ordinary illumination as small (but not minute) highly refractile particles under the microscope. The number of platelets in one or more area of $1 \mathrm{~mm}^{2}$ was calculated as follows:

Platelet count $/ 1=\frac{\text { Numbers of cells counted } \times \text { dilution } \times 10^{6}}{\text { Volume counted }}$

All patients were divided into two groups: (A) survivors and (B) nonsurvivors.

\section{Results}

Table 1 shows that in all the three groups in survivors gradual rise in platelet counts was observed on subsequent postburn days till discharge of these patients.

Table 2 Mean platelet count in nonsurvivors

\begin{tabular}{|c|c|c|c|c|c|c|c|}
\hline \multirow[t]{2}{*}{ S. No. } & \multirow[t]{2}{*}{ Burn groups } & \multirow[t]{2}{*}{ Number of patients } & \multicolumn{5}{|c|}{ Mean platelet count (in lakh/mm $/ \mathrm{m}^{3}$ ) } \\
\hline & & & 1st day & 3rd day & 7th day & 14 th day & 21 st day \\
\hline 1 & $20-30 \%$ & 27 & $2.08 \pm 0.13$ & $2.01 \pm 0.2$ & $1.9 \pm 0.2$ & $1.8 \pm 0.30$ & $1.5 \pm 0.78$ \\
\hline 2 & $31-40 \%$ & 06 & 1. $68 \pm 0.28$ & $1.54 \pm 0.16$ & $1.42 \pm 0.10$ & $1.11 \pm 0.5$ & $0.90 \pm 0.2$ \\
\hline 3 & $41-50 \%$ & 113 & $2.08 \pm 0.36$ & $1.83 \pm 0.68$ & $1.60 \pm 0.52$ & $1.61 \pm 0.41$ & $1.11 \pm 0.28$ \\
\hline 4 & $51-60 \%$ & 53 & $1.98 \pm 0.38$ & $1.61 \pm 0.41$ & $1.52 \pm 0.60$ & $1.26 \pm 0.6$ & $1.1 \pm 0.2$ \\
\hline \multirow[t]{2}{*}{5} & $61-70 \%$ & 57 & $1.96 \pm 0.30$ & $1.72 \pm 0.59$ & $1.42 \pm 0.43$ & $1.25 \pm 0.19$ & $0.70 \pm 0.3$ \\
\hline & Total & 256 & & & & & \\
\hline
\end{tabular}




\section{Percentage Burn Groups}

In nonsurvivors, gradual decline in platelet count was observed in every group (Table 2). Platelet count on any postburn day is not dependent on the extent of burns. Mean platelet count was decreased before death in every group of patients. For example, in nonsurvivors platelet count on the 14 th postburn day in $31-40 \%$ groups is $1.11 \pm 0.5 \mathrm{lakh} / \mathrm{mm}^{3}$, while it is $1.25 \pm 0.19 \mathrm{lakh} / \mathrm{mm}^{3}$ on the 14th postburn day in $61-70 \%$ groups. Similarly in survivors on the 7 th postburn day, mean platelet counts in $20-30 \%$ and $31-40 \%$ groups were $2.0 \pm 0.64 \mathrm{lakh} / \mathrm{mm}^{3}$ and $2.1 \pm 0.49 \mathrm{lakh} / \mathrm{mm}^{3}$, respectively. Thus, change in platelet count was not dependent on percentage of burns but depended on the presence of sepsis in the burn patient.

\section{Percentage Burn Group in Nonsurvivors}

Thus, in a significant number of nonsurvivors (62.11\%) platelet count was low before their death, and in a significant number of survivors $(86.09 \%)$ platelet count was normal before their discharge $(P<0.001)$ (Table 3).

The incidence of low platelet count in survivors is shown in Fig. 1 and in nonsurvivors is shown in Fig. 2.

Table 4 shows that, in the nonsurvivor group, nine patients expired on later date (after the 21 st post-burn day). Patient nos. 1 and 3 though died on later date, but platelet count in both patients was significantly decreased before their death. In patient nos. 2, 4, 6, and 7, declining trend of platelet count which occurred up to the 21 st postburn day was still maintained before their death.

In patient no. 5, platelet count was declining till the 21 st post-burn day. The patient had fever, tachycardia, and tachypnea on the 22nd day onward, persistently for 5 days. Antibiotics were started according to the culture and sensitivity report, and three blood transfusions were given. The patient improved clinically after the 30th day, and platelet count on the 44th day was $1.6 \mathrm{lakh} / \mathrm{mm}^{3}$. Signs of dehydration were persistently present. On the 54th day, her platelet count was $1.8 \mathrm{lakh} / \mathrm{mm}^{3}$. On the 56th day, she suddenly went into hypotension and died. So in this patient, chronic

Table 3 Correlation of platelet count in survivors and nonsurvivors

\begin{tabular}{llll}
\hline Platelet count & Survivors & Nonsurvivors & Total \\
\hline Low & $47(13.91 \%)$ & $159(62.11 \%)$ & $206(34.68 \%)$ \\
$\left(<1.5 \mathrm{lakh} / \mathrm{mm}^{3}\right)$ & & & \\
Normal & $291(86.09 \%)$ & $97(37.89 \%)$ & $388(65.325)$ \\
Total & 338 & 256 & 594 \\
\hline
\end{tabular}

$\chi^{2}=155.9, \mathrm{DF}=2, P<0.001$. a

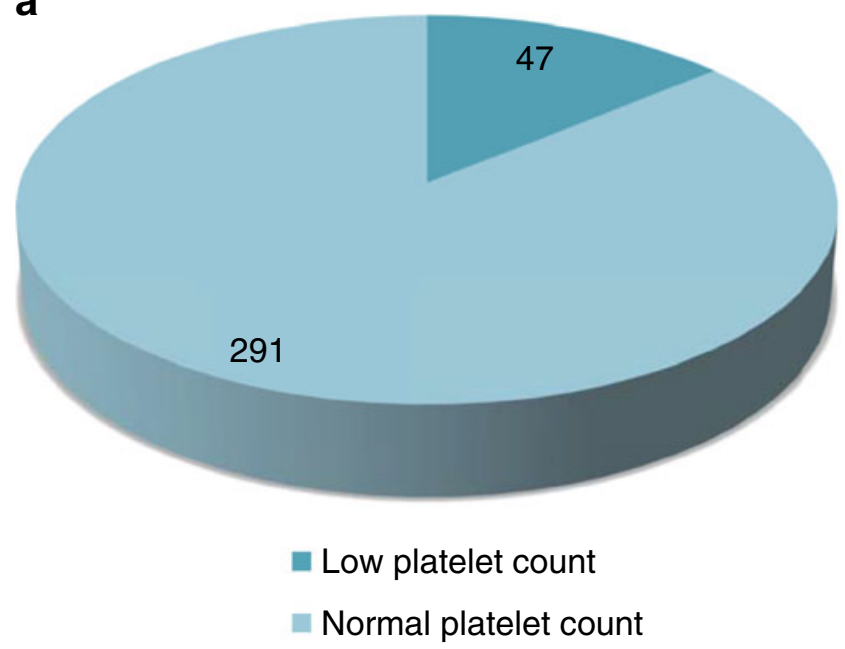

b

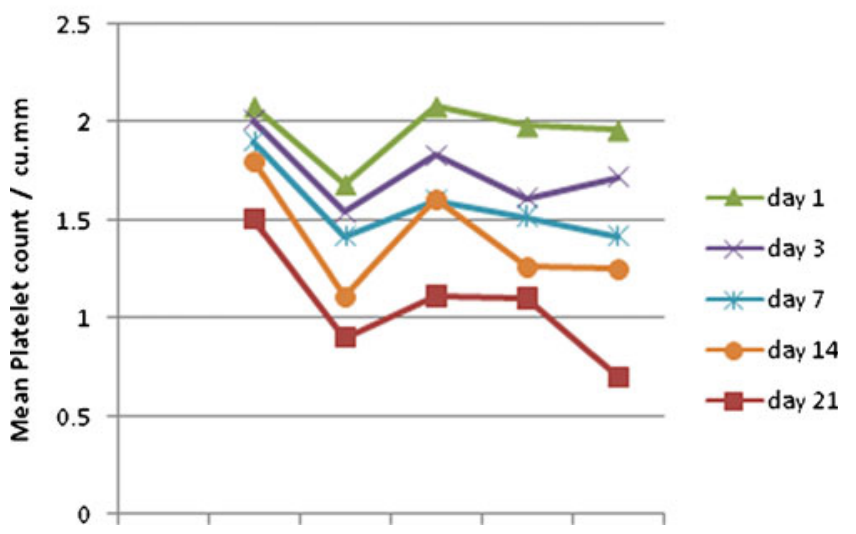

Fig. 1 a Pie digram showing incidence of low platelet count in survivors, $\mathrm{b}$ Trends in mean platelet counts in survivors

dehydration and poor intake were the contributory factors responsible for death rather than septicemia.

In patient nos. 8 and 9, though death occurred on the 23rd day, platelet count decreased to the low level on the $21 \mathrm{st}$ day. So it can be correlated to impending death of these patients. Similar results were observed in the other nonsurvivor group.

\section{Discussion}

In this study, it is found that predominant victims of burn injury are in the age group of 21-30 years. Social customs and problems like dowry might be the main factors in the young female population.

Survivors in the present study show decrease in platelet count in the initial post-burn days followed by rise in platelet count to the normal level on subsequent post-burn days. This finding coincides with similar observation in the 
a

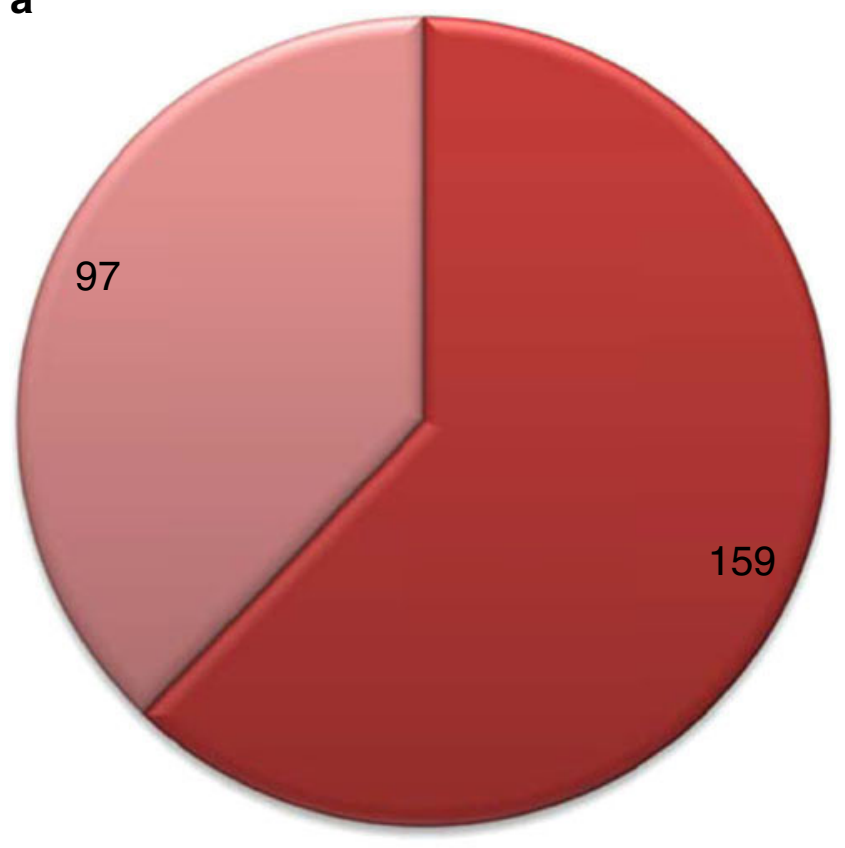

Low platelet count

$\square$ Normal platelet count

b

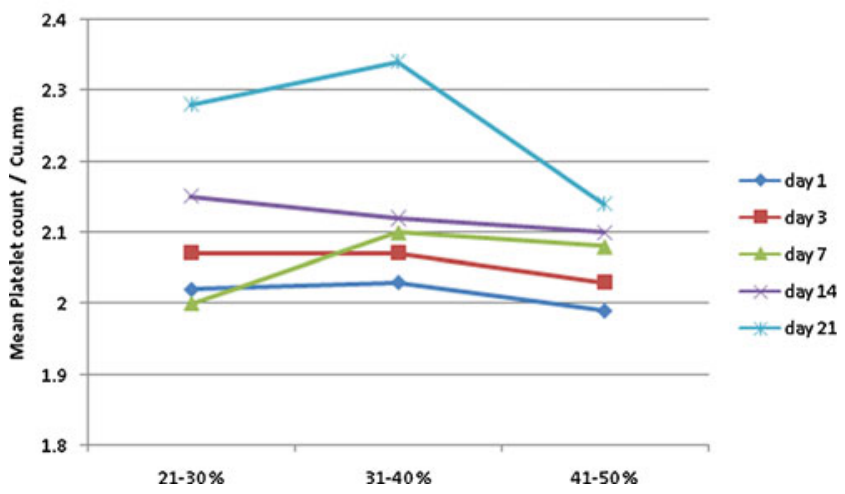

Fig. 2 a Pie digram showing incidence of low platelet count in nonsurvivors, $\mathbf{b}$ Trends in mean platelet counts in nonsurvivors
Table 5 Correlation between platelet count and survival of burn patients in different studies

\begin{tabular}{lllll}
\hline Studies & Platelet count & Survivors & Nonsurvivors & Total \\
\hline Maduli et al [10] & Low & 4 & 14 & 18 \\
& Normal & 10 & 4 & 14 \\
Housinger & Low & 14 & 31 & 45 \\
et al [11] & Normal & 18 & 01 & 19 \\
Sarda et al [8] & Low & 5 & 18 & 23 \\
& Normal & 31 & 11 & 43 \\
Cohen [9] & Low & 0 & 2 & 2 \\
& Normal & 4 & 0 & 4 \\
Our study & Low & 47 & 159 & 206 \\
& Normal & 291 & 97 & 388 \\
\hline
\end{tabular}

studies by other authors $[1,4,5,8,10]$. Of 32 burn patients, 14 survived having rebound increase in platelet count [8]. Of 30 patients in survivors, platelet count on the 7th post-burn day decreased below the normal level. Seventh day onward, it started increasing and reached up to $5.5 \mathrm{lakh} / \mathrm{mm}^{3}$ on the 15th post-burn day [4]. Thus, the rising trend in platelet count in survivors after initial fall coincides with this study.

In this study, every burn patient was followed up for 21 days (if no death occurs) and behavior of platelet count was studied. In nonsurvivors, declining trend in platelet count was observed with development and progression of septicemia. Thus, this declining platelet count can be correlated with bad prognosis of patients. Similar findings were observed by other authors $[1-3,5,7,8,10-12]$. They were observed for progressive decrease in platelet count on subsequent post-burn days in nonsurvivors. They correlated this observation with bad prognosis of the patient.

A retrospective cohort study examined survival outcomes at a burn unit of 54 beds and 10 burn ICU beds, totaling 900 admissions per year. A total of 102 adult patients admitted consecutively from January 1993 to October 2007 with massive burns (burn area $>70 \%$ of the total body surface area) were studied, and it was found that only sepsis,

Table 4 Pattern of platelet count in expired patients

\begin{tabular}{|c|c|c|c|c|c|c|c|c|}
\hline \multirow[t]{2}{*}{ S. No. } & \multirow[t]{2}{*}{ Extent of burn (\%) } & \multicolumn{5}{|c|}{ Mean platelet count $\left(\mathrm{lakh} / \mathrm{mm}^{3}\right)$} & \multirow[t]{2}{*}{ Fate expired } & \multirow[t]{2}{*}{ Platelet count $\left(\mathrm{lakh} / \mathrm{mm}^{3}\right)$} \\
\hline & & 1 st day & 3rd day & 7th day & 14th day & 21 st day & & \\
\hline 1 & 26 & 2.1 & 2 & 1.4 & 1.5 & 1.1 & 30th day & 28th day (1.1) \\
\hline 2 & 44 & 2.6 & 1.6 & 1.6 & 1.9 & 0.8 & 36th day & 35 th day $(0.8)$ \\
\hline 3 & 46 & 2 & 2.6 & 2.1 & 1.7 & 1.5 & 58th day & 54th day (1.2) \\
\hline 4 & 50 & 2.1 & 2.3 & 2.3 & 1.6 & 1.0 & 26th day & 26th day 1 \\
\hline 5 & 42 & 2.2 & 2 & 2.6 & 1.6 & 1.4 & 56th day & 54th day 1.8 \\
\hline 6 & 55 & 2 & 2.4 & 2.6 & 2.1 & 1.1 & 52 th day & 50th day (1.2) \\
\hline 7 & 68 & 1.8 & 1.6 & 1.2 & 1.4 & 0.6 & 28th day & 27 th day $(0.6)$ \\
\hline 8 & 30 & 1.9 & 2.3 & 2.4 & 2.1 & 0.9 & 23th day & Expired \\
\hline 9 & 44 & 1.9 & 2.3 & 1.6 & 2.3 & 1.0 & 23th day & Expired \\
\hline
\end{tabular}


ventilator dependency, and platelet counts were significant independent predictors of mortality as determined by multivariate analysis. It was observed that sepsis, ventilator dependence (indicating severe respiratory complications), and low platelet counts (indicating thrombocytopenia) were associated with increased mortality risk in adult patients with massive burns [12].

Septic burn patients with acute renal failure presented with severe proteinuria that correlated to outcome, glomerular (creatinine/urea clearance) and tubular (fractional excretion of sodium and potassium) functional impairment, and systemic inflammation (white blood cell and platelet counts). Proteinuria is a negative prognostic factor and an index of renal involvement in the systemic inflammatory reaction [13].

Significant difference in platelet count was revealed on the 4th and 7th days during monitoring in burn patient groups according to the severity of injury. A significant decrease in platelet count was observed in group B (moderate/severe burns) on day 4 as compared to day 1; platelet count was below the reference range. A significant increase in platelet count was observed on day 7 compared to day 4 in both groups according to severity of burn injury. A rising trend in platelet count further continued on day 14 compared to day 7 , but with no significant difference between groups [1].

Statistical significance of difference in mean platelet counts on different post-burn days in survivors and nonsurvivors was studied by using standard $t$-test. It was observed that difference in mean platelet count increased significantly on subsequent post-burn days. On the first day, the difference between the mean values of platelet count in survivors and nonsurvivors was statistically significant $(P=0.045)$. Similarly on $3 \mathrm{rd}$, 7 th, 14th, and 21st days, the difference between the mean values of platelet count in survivors and nonsurvivors was statistically significant $(P=0.000)$. Reason behind this is the gradual rise in platelet count in case of survivors and gradual decline in platelet count in case of nonsurvivors with occurrence and progression of septicemia which is comparable with study by others $[1,8]$.

Nonsurviving patients were significantly older and had larger burns. Nonsurviving patients also stayed longer in the unit. With regard to the cause of burn, nonsurvivors suffered significantly more flame injuries and self-damage. Further, nonsurviving patients needed more frequent catheterization and blood transfusion. In relation to laboratory findings, nonsurviving patients presented with more frequent anemia, hypoalbuminemia, thrombocytopenia, and a lower mean number of CD4+ cells (lymphocytes). The isolation of multiresistant bacteria or fungi in the wound was more likely in nonsurviving patients. Also, nonsurvivors had significantly more infectious complications $[2,8,12,13]$.

In our study of total 594 patients, 256 expired, so overall mortality is $43.10 \%$, which is low as compared to other studies $[1,4,8,11,13]$ in the same group of patients $(20$ $70 \%$ burns). Thus, a decline in mortality though not reduced significantly, but the survival of major burn patients was definitely increased due to commencement of timely management against sepsis (Table 5).

Thus, in conclusion, rebound rise in platelet count on the subsequent post-burn days occurs in survivors while declining trend is maintained till the death of the patients in case of nonsurvivors.

Platelet count on any post-burn day is not dependent on the extent of the burn injury but depends on sepsis in burns. The monitoring of the platelet count is of great importance during the resuscitation and care of severely burned patients. Whenever the platelet count begins to decline, all measures to support the general condition of the burned patient should be initiated, including the administration of intravenous fluids and antibiotics, optimal care of the burn wound, debridement or escharectomy, and blood transfusion, so serial platelet count in post-burn period can be used as a prognostic indicator in burnt patients.

Acknowledgement Dr.B.S.Gedam, MBBS, MS.GEN.Surgery, M.S.ortho, Professor in surgery, is heartily thanked for his technical assistance in the preparation of the manuscript.

Funding/Support Source None.

\section{References}

1. Pavic M, Milevoj L (2007) Platelet count monitoring in burn patients. Biochemia Medica 17(2):212-219

2. Macedo JLS, Santos JB (2007) Predictive factors of mortality in burn patients. Rev Inst Med Trop 49(6):365-370

3. Vilain RC (1977) Is the burn center a septic ghetto? Plast Reconstr Surg 59(5):793-794

4. El-Sonbaty MA, El-Otiefy MA (1996) Haematological change in severely burn patients. Ann Burns Fire Disasters 9(4):1-4

5. Yoshiaki T (1997) Blood platelet in severely injured burned patients. Burns 23(78):593-595

6. Caprini JA, Lipp V, Zuckerman L et al (1977) Hematologic changes following burns. J Surg Res 22(6):626-635

7. Eurenius K, Mortensen RF, Meserol PM et al (1972) Platelet and megakaryocyte kinetics following thermal injury. J Lab Clin Med 79(2):247-257

8. Sarda DK, Dagwade AM, Lohiya S et al (2005) Evauation of platelet count as a prognostic indicator in early detection of post burn septicaemia. Bombay Hosp J 47(3):3-6

9. Cohen P, Gardner FH (1966) Thrombocytopenia as a laboratory sign and complication of gram negative bacteremic infection. Arch Intern Med 117:113-123

10. Maduli IC, Patil A, Pardhan NR et al (1999) Evaluation of burn sepsis with reference to platelet count as a prognostic indicator. IJS 61(4):235-238

11. Housinger TA, Brinkerhoff C, Warden GD (1993) The relationship between platelet count, sepsis and survival in pediatric burn patients. Arch Surg 128:65-67

12. Wang Y, Tang HT, Xia ZF et al (2010) Factor affecting survival in adult patient with massive burn. Burns 36(1):57-64

13. Mariano F, Cantaluppi V, Stella M (2008) Circulating plasma factors induce tubular and glomerular alterations in septic burns patients. Crit Care 12:42 